\title{
Effect of TiC addition on the mechanical properties and microstructure of Al-Si alloy
}

\author{
O.O. Joseph *, A.S. Afolalu, A.A. Abioye, S.E. Agbo, S.F. Olatunde, O.S. Omotehinwa \\ Department of Mechanical Engineering, Covenant University, P.M.B. 1023, Canaanland, Ota, Nigeria
}

\section{A R T I C L E I N F O}

\section{Article history:}

Received 24 January 2020

Received in revised form 16 April 2020

Accepted 20 April 2020

Available online $\mathrm{xxxx}$

\section{Keywords:}

Nanoparticles

Composite

Stir casting

Aluminium

\begin{abstract}
A B S T R A C T
This study is focused on the development and characterization of a stir cast Al-Si alloy reinforced with titanium carbide nano-particles. The composite was developed using the stir casting method and the casted samples were prepared with TiC nano-particle at 0.4 (B1), 0.8 (B2), 1.2 (B3), 1.6 (B4) and 2.0 (B5) wt. \% of the entire composition, as well as a control sample, and thereafter subjected to tensile and hardness tests. It was noticed that none of the samples at the chosen concentrations brought about a greater hardness value than that of the control sample (Sample A), however they all show a positive trend with an increase in the \% wt. of reinforcement bringing about a possibility of increase in the hardness value. This suggests that a further increase above $2.0 \%$ of the reinforcement should bring about an increase in hardness above that of the base Al-Si alloy. On the other hand, the tensile strength was significantly increased upon reinforcement. B5 exhibited the highest tensile strength by displaying a transition from needles/plate-like to globular/fibrous morphology.

(c) 2020 Elsevier Ltd. All rights reserved.

Selection and peer-review under responsibility of the scientific committee of the International Symposium on Nanostructured, Nanoengineered and Advanced Materials. This is an open access article under the CC BY-NC-ND license (http://creativecommons.org/licenses/by-nc-nd/4.0/).
\end{abstract}

\section{Introduction}

The modification of materials and material properties with the use of nanoparticles has attracted widespread attention especially in the area of strength and stiffness improvement. Al-Si cast alloy is an encouraging material used primarily in automobile industry due to their great strength-to-weight ratio, exceptional castability and worthy mechanical properties. Such alloys blend outstanding mechanical characteristics and strong resistance to corrosion with fine castability [1-4]. The need for enhancement of properties of Al-Si based alloys has expressed importance due to the fact that at least $90 \%$ of aluminium castings are based on aluminium-silicon today. Being a binary alloy providing exceptional castability at low cost, aluminium-silicon based alloys are commonly used in numerous industries like for instance, the automotive industry [5]. Aluminium-based metal matrix composites and aluminium-silicon alloys have found usage in the production of a number of automotive engine machineries [6]. Based on these recent growths, there is a

\footnotetext{
* Corresponding author. Tel.: +2348035172086.

E-mail address: funmjoseph@gmail.com (O.O. Joseph).
}

demand for composite materials possessing great chemical and mechanical characteristics including toughness, improved corrosion resistance and high hardness [7]. Recently, researches on metal matrix composites (MMC) suggest that these materials display advantageous industrial applications owing to their high resistance to elevated temperature and greater strength-toweight ratio. These prompted researchers to focus on the development of reduced-cost products, especially metal matrix composite, which have improved features [8].

The utilization of Al-based cast alloys is currently on the increase. Although they possess great corrosion resistance accompanied with outstanding mechanical properties, the effect and contribution of reinforcement with nanoparticles however has not been extensively explored. Al-Si alloys lack adequate corrosion resistance and strength amongst other properties. The combination of strength and ductility has warranted the production of great strength $\mathrm{Al}-\mathrm{Si}$ alloys with noteworthy ductility in the recent times [9]. The aim of this research is to significantly improve certain properties of stir cast Al-Si alloys with the use of Titanium Carbide (TiC) nanoparticles modifiers. The research is further aimed at comparing the viability and benefits that the use of the selected nanoparticles has on Al-Si alloys and their properties. 


\section{Experimental procedure}

\subsection{Materials}

The materials (Aluminium, TiC nanoparticles) used for this work were purchased from the local market in Nigeria. The materials were taken to the foundry department where stir casting was done using a crucible furnace. TiC was added to the aluminium matrix composite according to the proportion listed in Table 1 . After casting, the as-cast material was machined into different small circular pieces in preparation for the tests as well as a standard tensile sample specification on which the tensile test would be carried out on. Also, a sample size of $1 \mathrm{~cm}$ by $1 \mathrm{~cm}$ by $1 \mathrm{~cm}$ was also machined and prepared for microstructure analysis.

\subsection{Hardness testing}

The Brinell Hardness Test was carried out with the aid of a TQ SM1000 Universal Testing Machine with a steel ball of $10 \mathrm{~mm}$ diameter indenter. A small circular sample was placed in a cavity aligned to the axis as the steel ball indenter, then the lever that drops the steel ball on the sample applying a form of hydraulic power is pulled, counting for $15 \mathrm{~s}$ and the reading of the applied force was displayed on the digital readout. Using a granule (magnifying glass with a measuring scale), the diameter of indentation was measured on the samples. The Brinell hardness value was calculated with the Brinell scale formula.

$$
\text { HBS }=0.102 \frac{2 F}{\pi D\left(D-\left(D^{2}-d^{2}\right)\right.}
$$

Where,

$$
\begin{aligned}
& \mathrm{F}=\text { Force applied }(130 \mathrm{kgf}) \\
& \mathrm{D}=\text { Diameter of Indenter, } \mathrm{mm} \\
& \mathrm{d}=\text { Diameter of Indentation, } \mathrm{mm}
\end{aligned}
$$

\subsection{Tensile testing}

The Tensile test was carried out with the aid of a TQ SM1000 Universal Testing Machine in accordance with ASTM E8/E8M-16a standard test method for tension testing of metallic materials. The material, machined in line with the dimensions in Fig. 1 was gripped at both ends and slowly pulled (using a form of hydraulic power) until it fractures. The initial peak force before applying the load was recorded as well as the final peak force after the material failed.

Table 1

Proportion for material preparation.

\begin{tabular}{lllll}
\hline $\mathrm{S} / \mathrm{N}$ & Specimen & Sub-specimen & $\% \mathrm{Al}-\mathrm{Si}$ & $\% \mathrm{TiC}$ \\
\hline 1. & $\mathrm{~A}$ & - & $100 \%$ & - \\
& MASS & $500 \mathrm{~g}$ & $500 \mathrm{~g}$ & - \\
2. & $\mathrm{~B}$ & $99.6 \%$ & $0.4 \%$ \\
& & $\mathrm{~B}_{5}$ & $498 \mathrm{~g}$ & $2 \mathrm{~g}$ \\
& MASS & $99.2 \%$ & $0.8 \%$ \\
& $\mathrm{~B}_{4}$ & $496 \mathrm{~g}$ & $4 \mathrm{~g}$ \\
& MASS & $98.8 \%$ & $1.2 \%$ \\
& $\mathrm{~B}_{3}$ & $494 \mathrm{~g}$ & $6 \mathrm{~g}$ \\
& MASS & $98.4 \%$ & $1.6 \%$ \\
& $\mathrm{~B}_{2}$ & $492 \mathrm{~g}$ & $8 \mathrm{~g}$ \\
& MASS & $98.0 \%$ & $2.0 \%$ \\
& & $\mathrm{~B}_{1}$ & $490 \mathrm{~g}$ & $10 \mathrm{~g}$ \\
\hline
\end{tabular}

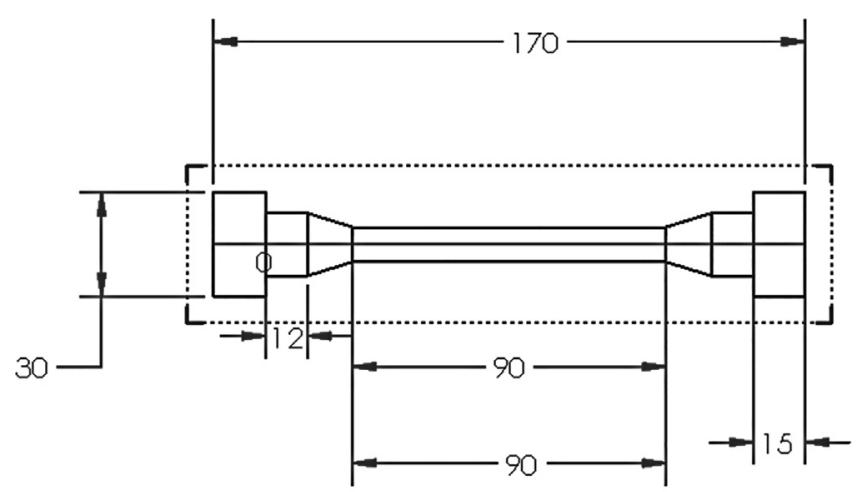

Fig. 1. Schematic of Tensile Test Specimen (all dimensions in $\mathrm{mm}$ ).

\subsection{Structural and morphological characterisation}

Scanning Electron Microscopy/Energy Dispersion Spectroscopic (SEM/EDS) studies were also carried out using a JSM-7600F Schottky Field Emission Scanning Electron Microscope.

For X-ray diffraction analysis, powdered samples were pelletized and sieved to $0.074 \mathrm{~mm}$. these were later taken in an aluminium alloy grid $(35 \mathrm{~mm} \times 50 \mathrm{~mm}$ ) on a flat glass plate and covered with a paper. Wearing hand gloves, the samples were compacted by gently pressing them with the hand. Each sample was run through the Rigaku D/Max-lllC X-ray diffractometer developed by the Rigaku Int. Corp. Tokyo, Japan and set to produce diffractions at scanning rate of $2^{\circ} / \mathrm{min}$ in the 2 to $50^{\circ}$ at room temperature with a CuKa radiation set at $40 \mathrm{kV}$ and $20 \mathrm{~mA}$. The diffraction data ( $\mathrm{d}$ value and relative intensity) obtained was compared to that of the standard data of minerals from the mineral powder diffraction file, ICDD which contained and includes the standard data of more than 3000 minerals.

\section{Results and discussion}

\subsection{Brinell hardness values}

From Fig. 2, it was observed that the control sample has the highest Brinell hardness value of $21.89 \mathrm{MPa}$ indicating that the addition of $\mathrm{TiC}$ at the selected concentrations failed to bring about an increase in the hardness of the sample. An explanation for this

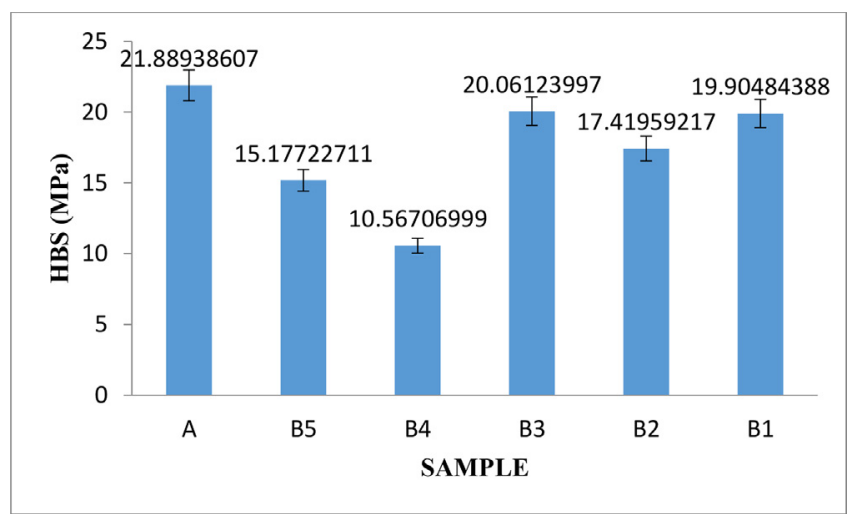

Fig. 2. Graph of Brinell hardness Test against all "B" samples (i.e. Samples containing Titanium Carbide) and sample "A" (Control). 


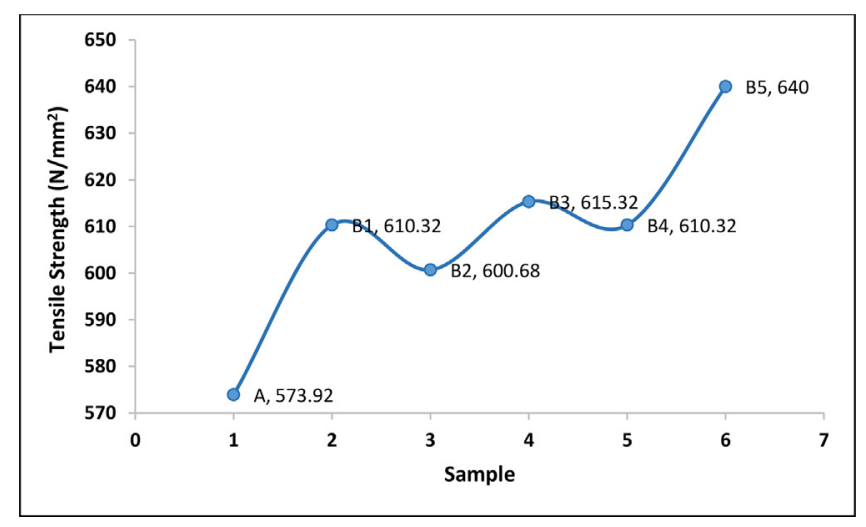

Fig. 3. Graph of Tensile Strength against all "B" samples (i.e. Samples containing TiC) and sample "A" (Control).

lies in the fact that aluminium matrix composites, being mostly reinforced with ceramics, have low toughness in comparison to the unreinforced aluminium and alloys [10].

However, a positive trend is noticed with a deviation in sample B4 (0.8 wt. \% TiC) and B2 (1.6 wt\% TiC), suggesting that a further increase in the volume fraction of TiC at concentrations higher than $2.0 \%$, would bring about Brinell hardness values greater than that of the Al-Si alloy, hence increasing its hardness. This is due to the increase in the volume fraction of the relatively hard-phase $\mathrm{Al}_{3}-\mathrm{Ti}[11]$.

\subsection{Tensile strength}

From Fig. 3, it is seen that sample B5 (2.0 wt\% TiC) has the highest tensile value of $6400 \mathrm{~N}$. It is also noticed that there is an increasing trend to the graph which proposes that an increase in the weight fraction of reinforcement ( $\mathrm{TiC}$ ) leads to an increase in strength of samples. All the aluminium composites have tensile strength values higher than the unreinforced aluminium alloy. The increase in the tensile strength is due to the applied tensile load transfer which is as a result of the strongly bonded TiC reinforcement in the Al-Si matrix [12]. This is a good indication that TiC has the ability to reinforce aluminium alloy.

\subsection{Microstructural analysis}

Fig. 4 shows the microstructure and EDS analysis of the Al-Si control sample. The sample image was taken at 4000X magnifica- tion, with acceleration voltage of $20 \mathrm{kV}$, working distance of $50 \mu \mathrm{m}$. The Figure reveals coarse plate-like hypoeutectic silicon in the aluminium matrix which can promote brittleness within the alloy [13].

The EDS shows the composition of the coating of the Al-Si sample, A. It shows the constituent element peaks and their wt \%. Al and Si peaks are noticed, which are the primary constituents of the specimen under consideration. Fig. 5(B1-B5) shows the scanning electron microscopic images of the Al-SiTiC alloy. The sample images were taken at $5000 \times$ magnification, with acceleration voltage of $20 \mathrm{kV}$, working distance between 10 and $20 \mu \mathrm{m}$. Fig. 5 reveals a finer grain structure owing to the fact that titanium functions as a grain refiner in Al alloys [8].

From the EDS, $\mathrm{Al}, \mathrm{Si}, \mathrm{Ti}$ and $\mathrm{C}$ peaks are noticed, which is consistent with the primary constituents of the composite produced. In B1, the reinforcing particles are well dispersed and clearly delineated in the aluminium alloy [10]. B2-B4 shows the dominance of hypoeutectic silicon. However, B5 further shows a transition from needles/platelike to globular/fibrous morphology, an evidence of improved mechanical property [12]. It is important to note that B5 exhibited the highest tensile strength and this is also confirmed by microstructural analysis.

\subsection{X-ray diffraction analysis}

Fig. 6 shows the XRD analysis of the samples (B1-B5). Peaks of aluminium and titanium are seen alongside other peaks. This indicates the formation of the phase $\mathrm{Al}_{3}$-Ti.

\section{Conclusions}

In this study, a metal matrix composite was developed from the alloy of aluminium and silicon reinforced with titanium carbide (TiC) making use of several material testing techniques. From the experiments concluded matched with experimental results, specific material properties like tensile strengths were enhanced with some superior to the monolithic material. Although precise material properties like hardness were not seen to progress by a large margin, it is suggested that upon further increase in the weight fraction of each reinforcement above $2.0 \%$, great progress is predicted and this alloy would be able to find applications where high tensile strength is needed.
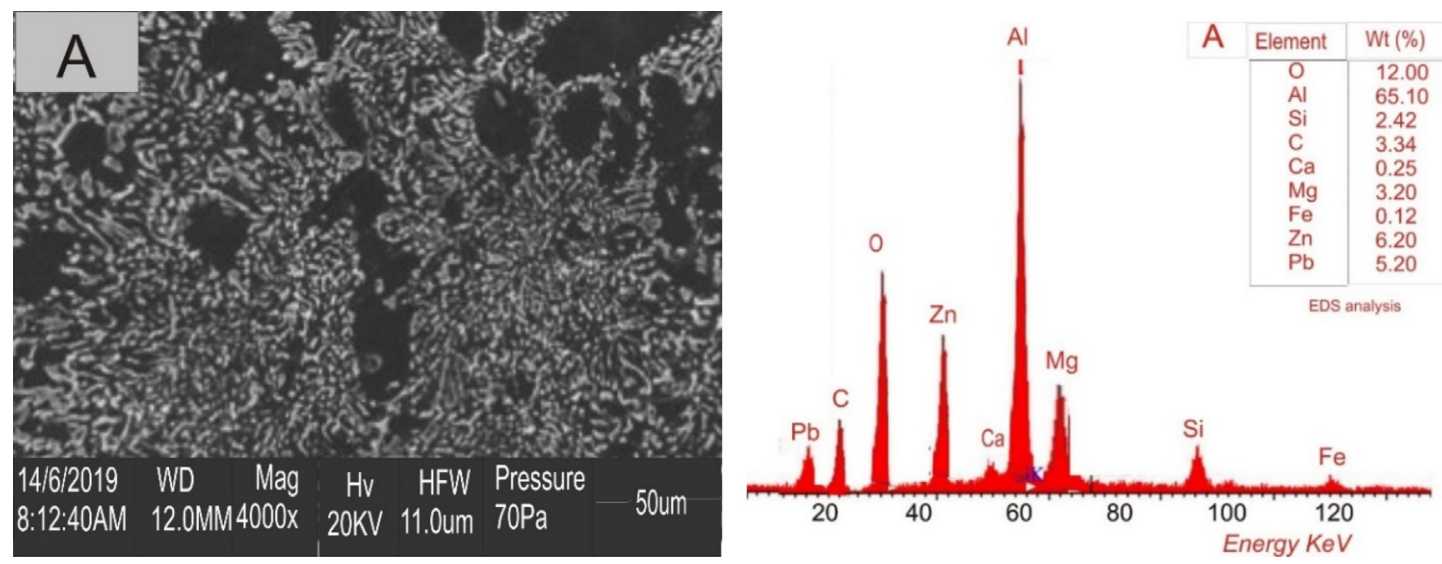

Fig. 4. SEM/EDS of Sample A (Al-Si alloy) [Control] at $4000 \times$ magnification. 

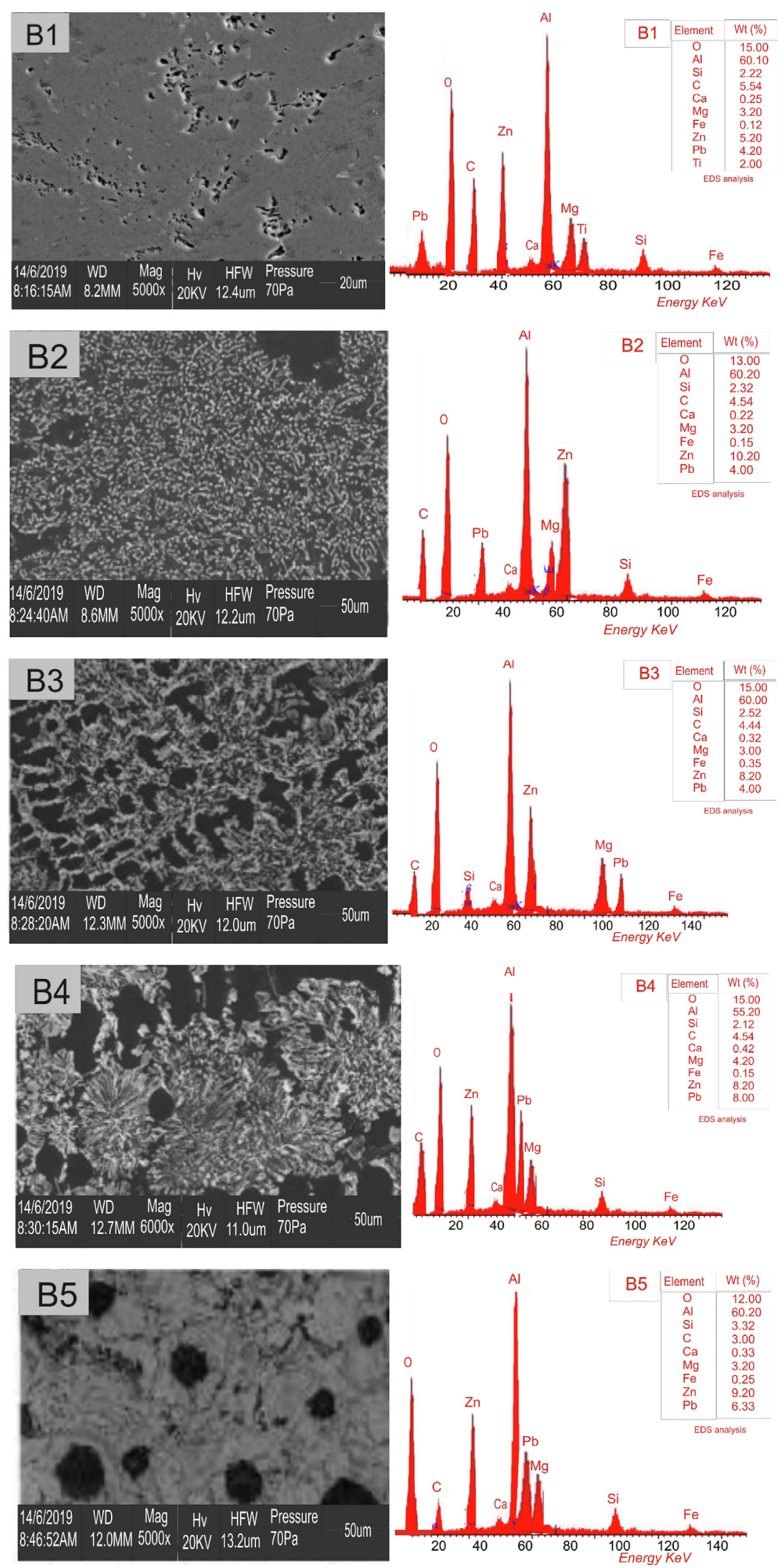

Fig. 5. SEM/EDS of Samples B1-B5 (Al-Si-TiC). 

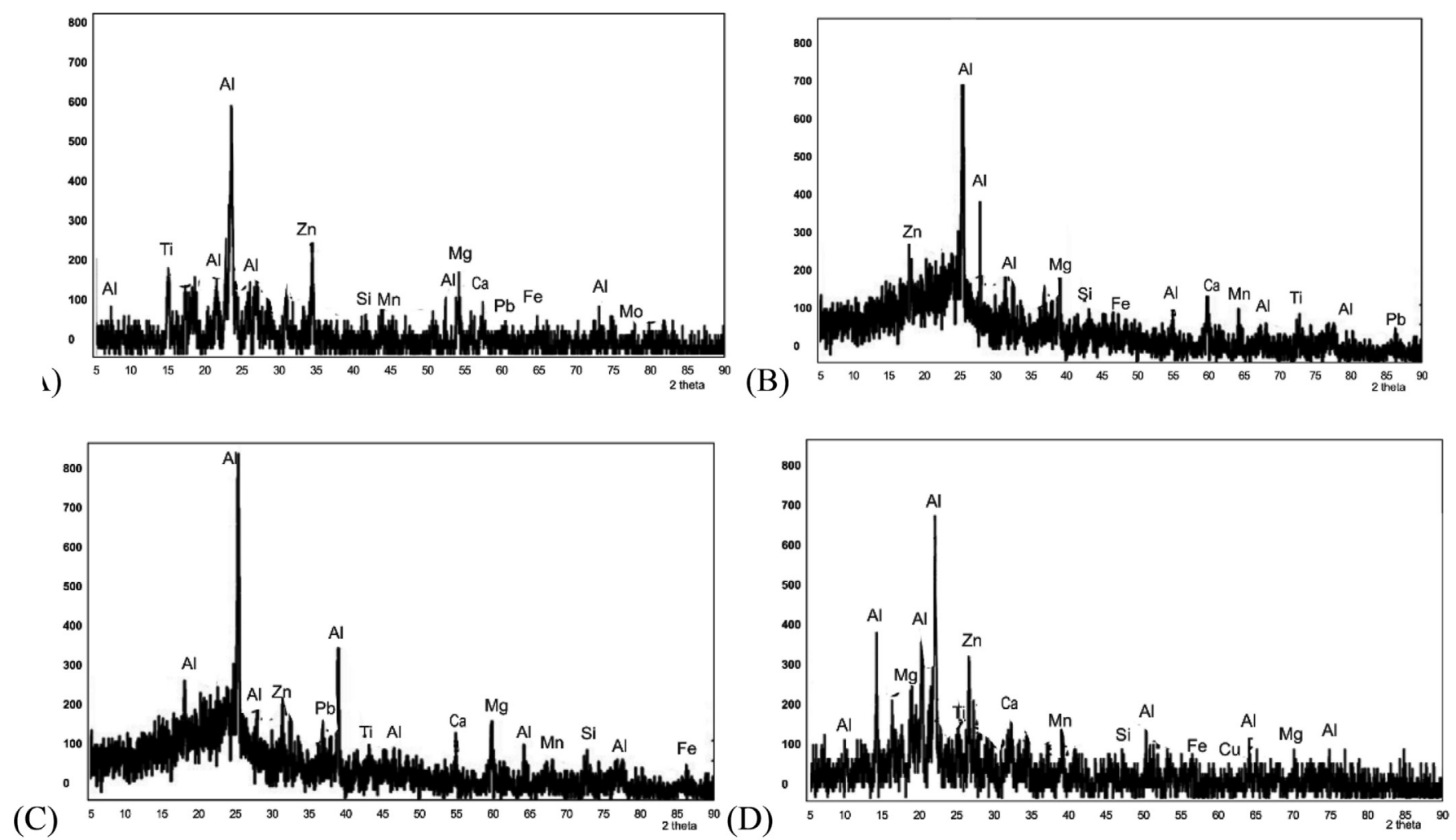

(E)

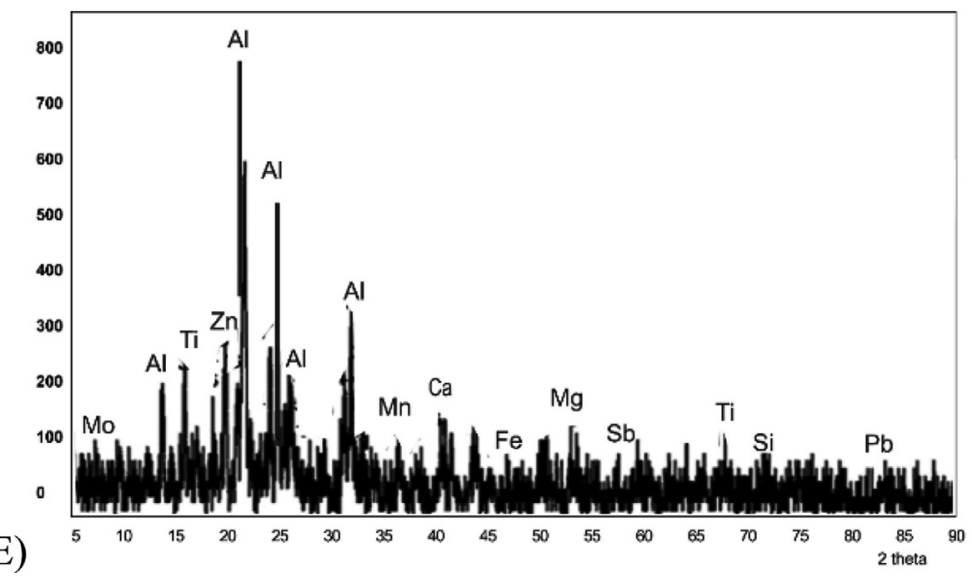

Fig. 6. XRD of samples (A) B1, (B) B2, (C) B3, (D) B4 and (E) B5 showing a predominant phase of $\mathrm{Al}_{3}-\mathrm{Ti}$.

\section{CRediT authorship contribution statement}

0.0. Joseph: Conceptualization, Writing - review \& editing. A.S. Afolalu: Visualization, Investigation. A.A. Abioye: Visualization, Investigation. S.E. Agbo: Investigation, Data curation. S.F. Olatunde: . O.S. Omotehinwa: Investigation, Data curation.

\section{Declaration of Competing Interest}

The authors declare that they have no known competing financial interests or personal relationships that could have appeared to influence the work reported in this paper.

\section{Acknowledgement}

Covenant University is acknowledged for the provision of the testing facility and funds used for this work.

\section{References}

[1] M. Zamani, Al-Si Cast Alloys-Microstructure and Mechanical Properties at Ambient and, Elev. Temperat. 2 (12) (2015) 56-60.

[2] F. Hafiz, T. Kobayashi, Nonmodified Properties Eutectic of Modified Alloys, Int. J. Global Adv. Mater. Nanotechnol. 598 (1994) 234-236.

[3] M. Farkasova, E. Tillova, M. Chalupova, FME Transactions. 41 (2013) 210-215.

[4] S.C. Hansen, C.R. Jr Loper, Calphad 24 (2000) 339-352.

[5] R. Sekhar, T.P. Singh, J. Mat. Res. Tech. 4 (2015) 197-207.

[6] M.M. Dave, K.D. Kothari, Indian J. Res. 2 (2013) 148-150.

[7] O.O. Joseph, K.O. Babaremu, Fibers. 7 (2019) 33.

[8] O.S.I. Fayomi, O.O. Joseph, I.G. Akande, C.K. Ohiri, K.O. Enechi, N.E. Udoye, J. Alloys Compd. 783 (2019) 246-255.

[9] S.Z. Han, E. Choi, H.W. Park, S.H. Lim, J. Lee, J.H. Ahn, N. Hwang, K. Kim, Sci. Rep. 7 (2017) 12195.

[10] K.K. Alaneme, A.V. Fajemisin, N.B. Maledi, J. Mat. Res. Tech. 8 (2019) 670-682.

[11] M. Zeren, E. Karakulak, J. Alloys Compd. 450 (2008) 255-259.

[12] S. Ji, D. Watson, Y. Wang, M. White, Z. Fan, Mater. Sci. Forum. 765 (2013) 2327.

[13] K.T. Kashyap, T. Chandrashekar, Bull. Mater. Sci. 24 (2001) 345-353. 